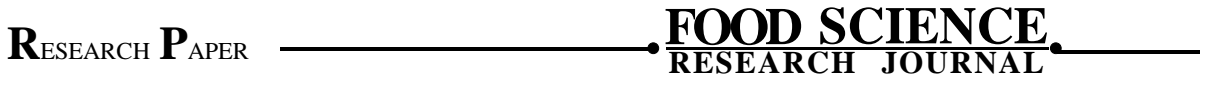

e ISSN-2230-9403 - Visit us : www.researchjournal.co.in Volume 8 | Issue 1 | April, 2017 | 43-46 DOI : $10.15740 / \mathrm{HAS} / \mathrm{FSRJ} / 8.1 / 43-46$

\title{
Nutritional status and physical activity among post- graduate hostel girls, University of Rajasthan, Jaipur
}

\author{
Monika, Sadia Chishty and Kanika Varma
}

\begin{abstract}
In the present study, an attempt has been made to report the Nutritional status and physical activity pattern in female students ( $\mathrm{n}=104)$ living in P.G. Hostel of University of Rajasthan, Jaipur. Assessment of nutritional status was done through $24 \mathrm{hr}$ dietary recall and anthropometric measurements (height, weight and BMI). Energy expenditure was calculated using two days $24 \mathrm{hr}$ recall and time spent in various activities. The physical activity pattern was assessed by using validated and standardized questionnaire. The prevalence of overweight and obesity was calculated by the critical limits of body mass index (BMI). The study indicated that 10 per cent P.G. Hostel girls were found pre obese and 10.5 per cent were in obese category. Their nutrient intake was also inadequate energy, iron and calcium were significantly lower while fat intake was significantly higher. They were falling in negative energy balance.
\end{abstract}

Key Words : Body mass index, Energy expenditure, Obesity, Overweight, Physical activity

How to cite this article : Monika, Chishty, Sadia and Varma, Kanika (2017). Nutritional status and physical activity among postgraduate hostel girls, University of Rajasthan, Jaipur. Food Sci. Res. J., 8(1): 43-46, DOI : 10.15740/HAS/FSRJ/8.1/43-46. 